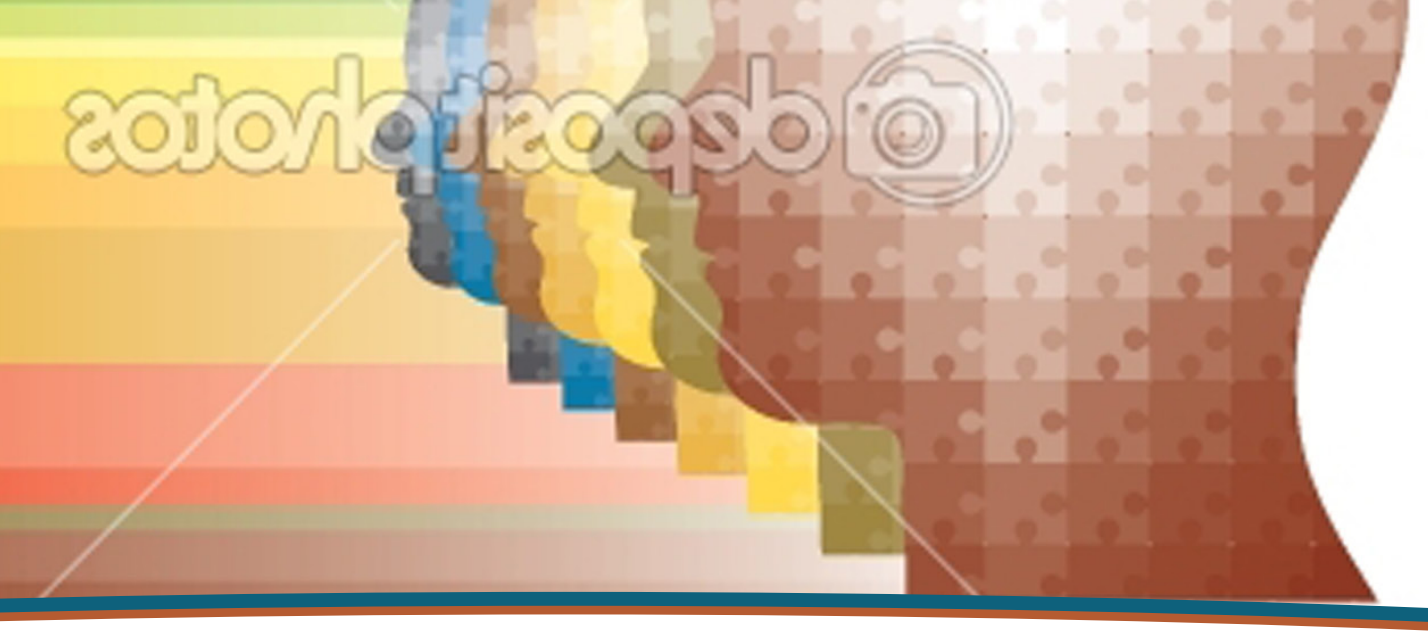

EIDOS, 5

Marzo - Agosto 2012, 5-11

ISSN:1390-499X

elSSN:1390-5007

\title{
Estilos de Aprendizaje
}

\author{
E. Díaz¹, Universidad Tecnológica Equinoccial
}

Recepción/Received: 2011-11-18

Aceptación/Accepted: 2012-05-10

Publicado/Published: 2012-08-20

Resumen - Este trabajo presenta una revisión teórica de los estudios realizados en torno al tema de estilos de aprendizaje y de pensamiento, y de sistemas de representación sensorial. El propósito es poner en evidencia la importancia de que en el proceso pedagógico, se utilicen estrategias metodológicas y recursos que respondan a los diferentes estilos y sistemas de representación, de manera que se favorezca el aprendizaje de todos los estudiantes, de acuerdo con su ciclo evolutivo, nivel de desarrollo y necesidades educativas, con la finalidad de elevar los niveles de motivación, fortalecer la calidad de los aprendizajes y conseguir un mejor rendimiento académico.

Palabras clave - Aprendizaje, Ciclo experiencial de aprendizaje, Desarrollo cognitivo, Estilos de aprendizaje, Estilos de pensamiento, Estrategias metodológicas, Programación neurolingüística, Sistemas de representación sensorial.

Abstract - This work offers a theoretical revision of studies that have been made about learning and thinking styles, and sensory representation systems. The purpose is to demonstrate the importance of using methodological strategies and resources in the learning process, responding to the different learning styles and representation systems, so that every student learning is met, according to their evolutionary cycle, development level, and learning needs, with the aim of increasing the motivation levels, strengthening the learning quality and obtaining a better academic performance.

Keywords - Cognitive development, Experiential Learning Cycle, Learning, Learning styles, Methodological strategies, Neurolinguistic programming, Sensory representation systems, Thinking styles.

1Elena Díaz Mosquera, dmen@ute.edu.ec, Docente de Posgrados, Universidad Tecnológica Equinoccial 


\section{INTRODUCCIÓN}

Con frecuencia, los resultados del trabajo escolar permiten evidenciar que, aún en circunstancias similares, no todos los niños y adolescentes logran el aprendizaje de una manera satisfactoria.

¿Qué se quiere decir con "circunstancias similares"? Por un lado, se refiere a características personales parecidas, que no difieren significativamente entre sí en cuanto a la dotación individual, por ejemplo todos los niños del grupo de clase pueden tener una misma necesidad educativa especial, o una capacidad intelectual dentro de ciertos parámetros (ser todos de nivel medio, o todos de nivel alto). Por otro lado, las "circunstancias similares" hacen referencia al hecho de que reciben las mismas experiencias de aprendizaje ofrecidas por los maestros a cargo.

¿Qué es lo que hace que unos niños aprendan más y otros menos, si los factores intervinientes, tales como características personales y experiencias de aprendizaje, parecen estar "bajo control"? La respuesta podría ser "la motivación". Entonces la pregunta sería: ¿Por qué unos niños se sienten más motivados que otros para el aprendizaje? ¿Será una cuestión de intereses o gustos? No se puede desconocer la importancia de las preferencias personales en el aprendizaje, pero ¿pueden los maestros intervenir de alguna manera en los intereses o preferencias de sus estudiantes?

Estas y otras interrogantes con respecto al rendimiento académico de estudiantes que aparentemente están en "circunstancias similares", parecen tener alguna explicación si se toman en cuenta los estilos de aprendizaje.

\section{EL APRENDIZAJE Y SUS ESTILOS}

El aprendizaje, como acto eminentemente humano, engloba una serie de procesos que han sido ampliamente estudiados desde diferentes perspectivas a través de la historia, con la finalidad de investigar en qué consiste, cómo ocurre, qué factores intervienen en él, cómo potenciarlo, entre otros temas de interés.

\section{A. El aprendizaje}

Al integrar lo que varios autores, a partir de sus investigaciones, han dicho sobre el aprendizaje, se puede concluir que se trata de una serie de procesos biológicos y psicológicos que ocurren en la corteza cerebral que, gracias a la mediatización del pensamiento, llevan al sujeto a modificar su actitud, habilidad, conocimiento e información, así como sus formas de ejecución, por las experiencias que adquiere en la interacción con el ambiente externo, en busca de dar respuestas adecuadas.

En la definición planteada se evidencian los tres aspectos que constituyen la esencia del ser humano: el componente biológico, el componente psicológico y el componente social. En el proceso de aprendizaje, lo biológico y lo psicológico representado por las funciones humanas superiores, entre ellas el pensamiento, interactúan con lo que el medio ambiente (el componente social) le ofrece, para llevar al sujeto que aprende a producir un cambio, una modificación que se manifiesta en su forma de comportarse, y cuyo fin es responder adecuadamente a las demandas del medio. Sin embargo, únicamente se puede hablar de "aprendizaje" cuando el cambio que se produce es duradero, para lo cual la práctica resulta imprescindible.

Como ejemplo, un niño que está en la situación de aprender a multiplicar necesita, en primer lugar, entender el proceso (entra en juego lo biológico y lo psicológico con la mediatización del pensamiento, gracias a la oportunidad de aprendizaje que su medio, lo social, le brinda); en segundo lugar, practica lo aprendido a través de juegos, de resolución de operaciones, de resolución de problemas, que el docente a cargo le ofrece; esta práctica le permite mecanizar la operación. Finalmente, aprende a multiplicar; este hecho será evidente cuando el niño, de manera totalmente espontánea, aplique la multiplicación para resolver problemas cotidianos que requieran de ella.

\section{B. Desarrollo cognitivo y aprendizaje}

Según los planteamientos de Jean Piaget, las personas atraviesan en su desarrollo cognitivo, por diferentes etapas (desde el nacimiento hasta la adultez) que sirven de base para los aprendizajes que se realizan. Para adaptarse a las situaciones de cambio que cada etapa cognitiva plantea, dados los progresos madurativos, se desarrollan dos procesos simultáneos en las estructuras cognitivas del ser humano:

El primero de ellos, la ASIMILACIÓN, consiste en la incorporación de nuevos acontecimientos e informacio 
nes a los esquemas cognoscitivos ya existentes en la persona. El segundo, la ACOMODACIÓN, se refiere al cambio que experimentan tales esquemas cognoscitivos a causa de la asimilación.

En el juego dinámico entre estos procesos, sostiene Piaget, aparece una contradicción cognoscitiva transitoria que hace que las estructuras antiguas avancen, gracias al aprendizaje, hacia estadios más altos y complejos en busca del PRINCIPIO DE EQUILIBRIO; para que esto ocurra, el ser humano modifica sus propios esquemas con la finalidad de dar coherencia al mundo percibido; el aprendizaje y su subsecuente principio de equilibrio se producen como resultado de la interacción del sujeto con el mundo físico y social. Este es un proceso que ocurre durante toda la vida, pues, recordando a Savater, todo acto humano es, en el fondo, un acto de enseñanza aprendizaje.

\section{Ciclo experiencial de aprendizaje}

Sobre la base de la teoría de Piaget, el doctor David Kolb de la Universidad de Massachussets, desarrolló en 1975 el MODELO EXPERIENCIAL, en el cual el aprendizaje es concebido como un ciclo de cuatro etapas, que funciona como un espiral continuo.

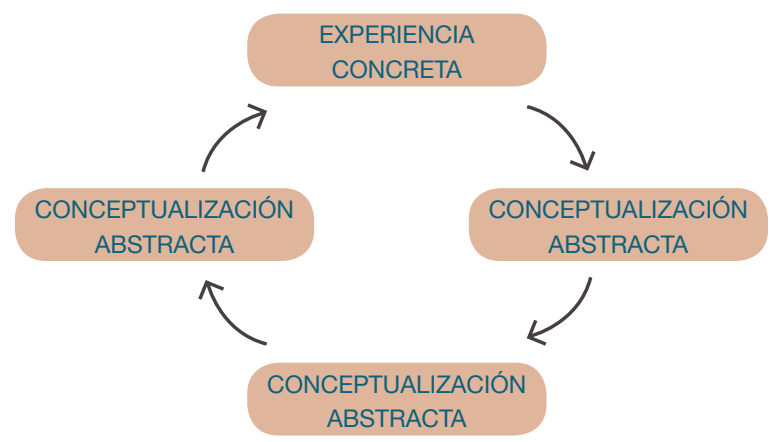

Figura 1. Etapas del ciclo de aprendizaje experiencial de David Kolb

Estas cuatro etapas son: Experiencia concreta, Observación reflexiva, Conceptualización abstracta y Experimentación activa.

La idea es que cada tema de aprendizaje sea abordado a través de las cuatro etapas para que éste realmente ocurra y sea significativo para el sujeto que aprende. Así, en la experiencia concreta los estudiantes interactúan con el objeto de estudio a fin de conocerlo en el plano concreto, vivencial. La observación reflexiva les permite extraer algunas ideas y pensar sobre ellas, a partir de los hechos observados en el objeto de estudio. En la conceptualización, que es ya de carácter abstracto, los estudiantes contrastan lo observado con la información sobre el tema (que puede provenir de un texto, de un video, de la explicación del maestro, según el caso, o incluso combinando técnicas), lo cual les permite caracterizar al objeto mediante sus regularidades, y formular definiciones. Finalmente, los estudiantes ponen en práctica lo aprendido y lo transfieren a otros contextos, mediante la experimentación activa.

Según Kolb, es importante que todo aprendizaje utilice las cuatro etapas del ciclo, puesto que por sus circunstancias particulares, relacionadas con su dotación individual, preferencias y gustos, cada estudiante se sentirá más cómodo con alguna de ellas. De esta manera, quien prefiere la etapa de experiencia concreta, es un alumno ACTIVO, que aprende experimentando; aquel que prefiere la etapa de observación reflexiva, es un alumno REFLEXIVO, que aprende reflexionando; el que prefiere la etapa de conceptualización abstracta, es un alumno TEÓRICO, que aprende pensando; quien prefiere la etapa de experimentación activa, es un alumno PRAGMÁTICO, que aprende haciendo.

\section{Estilos de aprendizaje}

A partir del modelo experiencial de aprendizaje, David Kolb y su colega Roger Fry crearon en 1995 los ESTILOS DE APRENDIZAJE, bajo la concepción de que, según las características de cada estudiante, alguna de las combinaciones de las etapas del ciclo favorece más su aprendizaje que las otras.

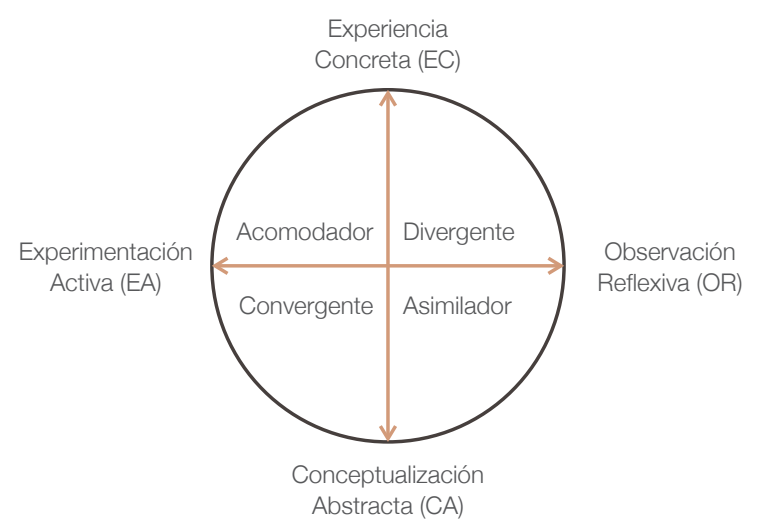

Figura 2. Estilos de aprendizaje; Disponible en: www.jlgcue.es

Como se puede observar en la Figura 2, de acuerdo con los planteamientos de Kolb, un estudiante que 
aprende mejor combinando la experiencia concreta con la observación reflexiva, tiene un estilo de aprendizaje DIVERGENTE; un estudiante que prefiere aprender combinando la observación reflexiva con la conceptualización abstracta, tiene un estilo de aprendizaje ASIMILADOR; el estudiante que aprovecha más al combinar la conceptualización abstracta con la experimentación activa, es de estilo CONVERGENTE; finalmente, aquel que aprende mejor combinando la experimentación activa con la experiencia concreta, demuestra un estilo de aprendizaje ACOMODADOR. Existe también la posibilidad de que algunos estudiantes tengan más de un estilo de aprendizaje.

El estilo DIVERGENTE se caracteriza por su capacidad imaginativa y por la producción de ideas; en general, los estudiantes divergentes son kinestésicos (aprenden con el movimiento), son experimentales, creativos, flexibles, informales, tienden a romper las normas tradicionales de aprender.

El estilo de aprendizaje ASIMILADOR se caracteriza por su capacidad para crear modelos teóricos; los estudiantes que prefieren este estilo, son, por lo regular, reflexivos, analíticos, organizados, metódicos, sistemáticos, lógicos, racionales, secuenciales, rigurosos en sus procesos de razonamiento; tienden a concentrarse en el objeto de estudio.

El estilo de aprendizaje CONVERGENTE se caracteriza por la aplicación práctica de ideas; en general, los estudiantes convergentes entran fácilmente al tema en estudio, se involucran en experiencias relacionadas con él, tienen habilidad para captar ideas y para encontrar soluciones, son prácticos, eficientes en la aplicación y transferencia de la teoría.

El estilo de aprendizaje ACOMODADOR se caracteriza por la capacidad para adaptarse a circunstancias inmediatas específicas. Los estudiantes acomodadores son, en general, observadores, atentos a los detalles, imaginativos, intuitivos a la hora de anticipar soluciones, son emocionales, con gran capacidad para relacionar y enlazar unos contenidos con otros.

Si cada estilo de aprendizaje tiene características particulares como las mencionadas, que pueden ser observadas en la forma de aprender de cada estudiante, es lógico suponer que hay estrategias metodológicas que benefician más el aprendizaje según el estilo propio de cada alumno. La tabla I muestra algunas de las estrategias propuestas por Kolb y sus seguidores.

Estas estrategias pueden utilizarse en el aula de clase de una manera combinada, de modo que se beneficie el aprendizaje de todos los estudiantes, teniendo siempre en cuenta las particularidades del grupo, en cuanto a ciclo evolutivo, nivel de desarrollo y necesidades educativas. Por ejemplo, para abordar un tema de ciencias sociales en educación básica, se pueden integrar varias actividades:

- Lluvia de ideas para ver lo que los estudiantes conocen sobre el tema y observación analítica de un video (beneficia al estilo divergente);

- Observación de campo con guía de trabajo y análisis de la información recolectada (beneficia al asimilador);

- Elaboración de organizadores de información y de gráficos (beneficia al convergente);

- Construcción de un producto, puede ser una composición, un trabajo de arte, una maqueta (beneficia al acomodador).

\section{TABLA I \\ ESTRATEGIAS METODOLÓGICAS SEGÚN EL ESTILO DE APRENDIZAJE}

\begin{tabular}{|c|c|}
\hline $\begin{array}{c}\text { ESTILOS DE } \\
\text { APRENDIZAJE }\end{array}$ & ESTRATEGIAS METODOLÓGICAS \\
\hline $\begin{array}{l}\text { DIVERGENTE } \\
(\text { EC + OR })\end{array}$ & $\begin{array}{l}\text { Lluvia de ideas, ejercicios de simulación, uso de } \\
\text { analogías, realización de experimentos, resolu- } \\
\text { ción de adivinanzas, crucigramas, rompecabe- } \\
\text { zas, construcción de organizadores de informa- } \\
\text { ción (mapas mentales, conceptuales). }\end{array}$ \\
\hline $\begin{array}{l}\text { ASIMILADOR } \\
(\mathrm{OR}+\mathrm{CA})\end{array}$ & $\begin{array}{l}\text { Análisis de textos, ordenamiento de datos, parti- } \\
\text { cipación en debates, realización de investigacio- } \\
\text { nes y consultas, elaboración de informes. }\end{array}$ \\
\hline $\begin{array}{c}\text { CONVERGENTE } \\
(\mathrm{CA}+\mathrm{EA})\end{array}$ & $\begin{array}{l}\text { Actividades manuales, elaboración de gráficos y } \\
\text { mapas, clasificación de información, resolución } \\
\text { de problemas, demostraciones prácticas. }\end{array}$ \\
\hline $\begin{array}{c}\text { ACOMODADOR } \\
(E A+E C)\end{array}$ & $\begin{array}{l}\text { Expresión artística, uso de la imaginación, activi- } \\
\text { dades de periodismo, trabajos grupales, discu- } \\
\text { sión socializada, elaboración de composiciones. }\end{array}$ \\
\hline
\end{tabular}

Aunque los estudiantes de una misma aula posean características similares en cuanto a su dotación individual y a sus necesidades educativas, sus estilos de aprendizaje suelen ser diversos, de allí la necesidad de que el docente a cargo utilice el ciclo de aprendizaje experiencial e incorpore estrategias metodológicas que 
beneficien a todos los estilos. De esta manera, podrá influir positivamente en el nivel de motivación, de interés, de involucramiento y, por lo tanto, de aprendizaje de sus estudiantes.

\section{E. Sistemas de representación sensorial}

Los órganos de los sentidos son nuestra ventana al mundo. Conocemos lo que nos rodea a través de los mensajes que ellos envían a nuestro cerebro, el cual se encarga de decodificar e interpretar la información recibida. Vemos, escuchamos, olfateamos, degustamos, tocamos, y todo aquello moviliza pensamientos y emociones.

La Programación Neurolingüística (PNL) es un enfoque de aprendizaje y de terapia que surgió a partir de los postulados de Richard Bandler y John Grinder. Se fundamenta en tres componentes: la PROGRAMACIÓN que se refiere a la aptitud humana de producir y utilizar programas de comportamiento; el componente NEUROLÓGICO conformado por las percepciones sensoriales que determinan el estado emocional propio de cada persona; y el componente LINGÜÍSTICO referido a la comunicación verbal y no verbal.

La PNL agrupa a las percepciones sensoriales humanas en tres sistemas principales de representación: el sistema visual, el sistema auditivo y el sistema kinestésico; este último integra las emociones con las sensaciones táctiles, gustativas y olfativas. De acuerdo con los planteamientos de la PNL, las personas tienen un sistema de representación dominante o primario, el cual se evidencia en su fisiología, en su conducta, en su forma de comunicación y en su comportamiento no verbal; también hay personas en las cuales se combinan dos sistemas.

El sistema de representación sensorial dominante tiene un papel importante en el proceso de aprendizaje. Un estudiante se sentirá más interesado y aprenderá mejor si el maestro utiliza y pone a su disposición el canal sensorial de su preferencia en las experiencias de aprendizaje.

Así, si en un niño el sistema dominante es el visual, las explicaciones o indicaciones verbales deben estar siempre acompañadas de imágenes o gráficos, caso contrario, el niño no logrará acceder a toda la información entregada y tendrá la tendencia a olvidar las instruc- ciones dadas. Del mismo modo, un niño cuyo sistema de representación sensorial dominante es el auditivo, necesitará que las imágenes de textos, carteles o videos vayan acompañadas de consignas verbales, con la finalidad de potenciar el nivel de comprensión. Los estudiantes que tienen como sistema sensorial dominante al kinestésico, requerirán que las situaciones de aprendizaje incluyan movimiento, o experiencias táctiles, gustativas u olfativas, o que movilicen sus emociones; son niños que tienen dificultad para aprender sin contacto o desde un puesto fijo dentro del aula. En la Tabla 2 que está a continuación, se presentan algunas características que, según la PNL, se pueden observar en las personas de acuerdo con su sistema de representación sensorial dominante.

\section{TABLA II}

\section{CARACTERÍSTICAS DE LOS ESTUDIANTES SEGÚN EL SISTEMA DE REPRESENTACIÓN SENSORIAL DOMINANTE}

\begin{tabular}{|c|c|}
\hline $\begin{array}{c}\text { S DE R S } \\
\text { DOMINANTE }\end{array}$ & CARACTERÍSTICAS \\
\hline VISUAL & $\begin{array}{l}\text { Piensan con imágenes. Hablan y escriben rá- } \\
\text { pidamente porque tienen la percepción de que } \\
\text { el tiempo no les alcanza para decir y/o escribir } \\
\text { todo lo que está en su pensamiento. Pueden } \\
\text { pensar en varias cosas simultáneamente, sin } \\
\text { que éstas tengan una secuencia. Pueden hacer } \\
\text { varias cosas al mismo tiempo. Necesitan mirar y } \\
\text { ser mirados y mantener contacto visual con sus } \\
\text { interlocutores. }\end{array}$ \\
\hline AUDITIVO & $\begin{array}{l}\text { El proceso de pensamiento es ordenado y se- } \\
\text { cuencial. Piensan en una idea, luego la mueven } \\
\text { para darle lugar a la siguiente. Hablan más lento } \\
\text { que los visuales. Hacen una cosa a la vez. Para } \\
\text { expresarse, eligen las palabras adecuadas que } \\
\text { reflejan con bastante precisión lo que están pen- } \\
\text { sando. Necesitan escuchar y ser escuchados y } \\
\text { recibir retroalimentación oral. }\end{array}$ \\
\hline KINESTÉSICO & $\begin{array}{l}\text { Se involucran en aquello que hacen, aún en me- } \\
\text { dio de las distracciones del entorno. Les agrada } \\
\text { participar con sus acciones y opiniones. Tienen } \\
\text { facilidad para percibir y expresar sus estados } \\
\text { internos, tales como sensaciones y emociones. } \\
\text { Piensan de acuerdo con lo que sienten. Nece- } \\
\text { sitan y buscan el contacto físico con los demás } \\
\text { (palmadas en la espalda, estrechar las manos, } \\
\text { abrazar). }\end{array}$ \\
\hline
\end{tabular}

Dado que en el aula, aún en circunstancias similares, cada estudiante tiene un sistema de representación sensorial dominante, es necesario que en las clases se incorporen estrategias metodológicas que favorezcan a los tres tipos, por lo tanto, las situaciones de 
aprendizaje deben incluir recursos visuales, auditivos, táctiles, de movimiento y, de ser posible, olfativos y gustativos (por ejemplo, cuando se trabajan temas relacionados con alimentación); así mismo, se debe tratar de movilizar emociones positivas, las cuales influyen significativamente en la motivación y el interés por el tema en estudio.

\section{F. Estilos de pensamiento}

En el año 1999, el psicólogo estadounidense Robert Sternberg presenta los "estilos de pensamiento". Con ello se refiere a la manera preferida por cada persona para emplear sus aptitudes. "Aptitud se refiere a lo bien que alguien puede hacer algo. Estilo se refiere a cómo le gusta a alguien hacer algo" (Sternberg, 1999, p. 24).

En su teoría del "autogobierno mental", Sternberg habla de funciones, formas, niveles, orientaciones y tendencias del pensamiento individual. El gráfico a continuación recrea esta teoría:

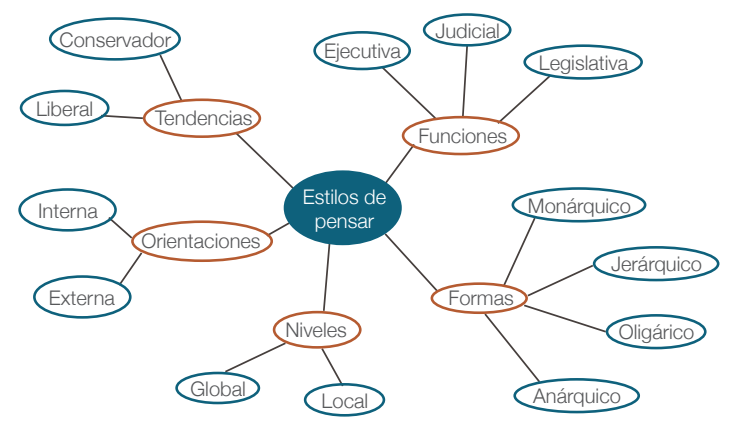

Figura 3. Estilos de Pensamiento; Disponible en: www.cca.org.mx/profesores/cursos/cep21-tec/modulo_2/modelo_robert_sternberg.htm

Según Sternberg, aunque varias personas tengan las mismas aptitudes, cada una tendrá su propio perfil de estilos de pensamiento, de acuerdo con las combinaciones que estén presentes. "No tenemos un estilo, sino un perfil de estilos. Las personas pueden ser prácticamente idénticas en cuanto a sus aptitudes y aun así tener estilos muy distintos", sostiene Sernberg (1999, p. 38).

Así, alguien podría ser legislativo en cuanto a su función, jerárquico respecto de su forma, de nivel global, de orientación externa, de tendencia liberal; mientras que otra persona con las mismas aptitudes podría exhibir un perfil diferente de pensamiento; podría por ejemplo ser ejecutivo en lugar de legislativo, monárquico en vez de jerárquico, local y no global, de orientación interna y no externa, y conservador en lugar de liberal.

Nuevamente, la idea de perfiles de estilos de pensamiento propuesta por Sternberg, nos plantea la necesidad de utilizar estrategias metodológicas variadas, con la finalidad de que cada estudiante, único y original en su forma de aprender y de pensar, se beneficie del aprendizaje.

\section{CONCLUSIONES}

Se ha dicho que todas las personas tienen un estilo de aprendizaje propio, un sistema de representación sensorial dominante, y un perfil de estilos de pensamiento. Esta condición no sólo se aplica a los estudiantes, sino también a los maestros, de allí que cada docente tienda a enseñar de la forma en la que él aprende.

Sin embargo, la incorporación en el proceso pedagógico de recursos y estrategias para todos los estilos de aprendizaje, para todos los sistemas de representación sensorial, y para todos los perfiles de estilos de pensamiento es una herramienta que le va a permitir al docente intervenir positivamente en el interés y la motivación de sus estudiantes, quienes, al involucrarse más, van a mejorar su nivel de aprendizaje y su rendimiento académico.

Por supuesto, como ya se ha mencionado, los recursos y las estrategias que el maestro utilice, tienen que guardar relación con el ciclo evolutivo de los estudiantes, con sus niveles de desarrollo y con sus necesidades educativas, ya sea que se trate de grupos altos, medios, bajos o especiales.

Puesto que cada acto humano supone de alguna manera un proceso de enseñanza aprendizaje, ninguna persona, cualquiera que sea su condición en cuanto a dotación individual, escapa a este proceso. Es, por lo tanto, una responsabilidad social, el empleo de los mejores medios para conseguir que más niños se beneficien de la posibilidad de aprender.

Es fundamental también tomar en cuenta que, dados los avances tecnológicos actuales, los estímulos visuales interactivos deben ser incorporados y utilizados en el aula de clase como un recurso importante, capaz de enganchar el interés del aprendiz al tema de estudio. 


\section{BIBLIOGRAFÍA}

[1] C. Alonso, Los estilos de aprendizaje. Procedimientos de diagnóstico y mejora, Bilbao, Ediciones Mensajero, 2000.

[2] D. Schunk, Teorías del Aprendizaje, Prentice Hall Hispanoamericana, 1997.

[3] E. García, Pedagogía constructivista y competencias, México, Editorial Trillas, 2010.

[4] F. Savater, El valor de educar, Bogotá, Editorial Ariel, 2000.

[5] J. Piaget, Psicología de la Inteligencia, Buenos Aires, Editorial Ariel, 1980.

[6] R. Alcudia, Atención a la diversidad, Caracas, Editorial Laboratorio Educativo, 2000.

[7] R. Sternberg, Estilos de pensamiento, Barcelona, Ediciones Paidós Ibérica S.A., 1999.

[8] V. Arancibia, Manual de Psicología Educacional, Santiago de Chile, Impresos Universitarios S.A., 2000.

[9] D. Kolb, "Inventario de Estilos de Aprendizaje," en Jornadas de Conferencias sobre Orientación Vocacional”, UDLA, Quito, 2002.

[10] L. Mudarep, "Creando nuevos mundos en Educación", en $1^{\circ}$ Congreso Internacional de Programación Neurolingüística, Escuela Argentina de PNL y Coaching, SINERKAP S.A., Quito, 2006.

[11] Google Imágenes, Cuatro estilos de aprendizaje de Kolb, Disponible en: www.jlgcue.es

[12] M. Smith, David A. Kolb on experiential learning, the enciclopedia of informal education, 2001, Disponible en: www.infed.org/biblio/b-explrn.htm

[13] Robert Sternberg: los perfiles de estilos y la inteligencia, Disponible en: http://www.cca.org.mx/profesores/cursos/cep21-tec/modulo_2/modelo_robert_sternberg.htm

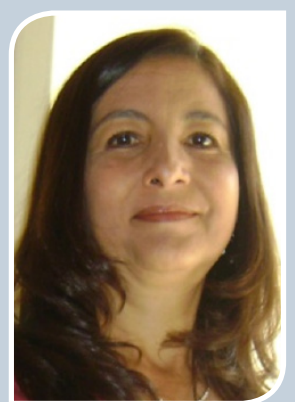

Elena Díaz Mosquera

Se graduó de Licenciada en Psicología especialización Clínica en la Pontificia Universidad Católica del Ecuador, Quito. Tiene tres Diplomados Superiores: Gerencia y Liderazgo en Educación, Currículo y Didáctica, e Investigación Educativa. Tiene un título de Magíster en Educación.

Es docente de la Maestría de Educación Especial de la Universidad Tecnológica Equinoccial. Dirige talleres y seminarios de capacitación para maestros, psicólogos, padres de familia, sobre temas relacionados con educación y psicología. Tiene una amplia experiencia laboral en instituciones educativas de nivel básico y medio.

Ha realizado investigaciones y publicaciones sobre temas psicoeducativos, entre ellos: Desarrollo socio afectivo, Acoso Escolar, Autismo en educación. 